\title{
Traveling between worlds: repositioning methods and theory for research into coupled socio-ecological systems
}

\author{
Lasse Gerrits
}

Received: 4 June 2020/ Accepted: 19 October 2021

(C) The Author(s) 2021

\begin{abstract}
Context This paper engages with the question of how one can arrive at more coherent explanations of social behavior in coupled socio-ecological systems.

Objectives The paper aims to give a counterargument to the assumption that social theory in coupled socio-ecological systems can only be developed in one way, as such showing that the premise of the special issue deserves further scrutiny.

Methods Current issues are identified and categorized based on a literature survey; likewise, the solutions derive from methodological literature, in particular from the realm of critical realism.

Results The paper shows how a set of assumptions about the nature of socio-ecological systems and about the nature of theory derived from observations prohibit a deeper understanding of how social theory may be developed at the nexus of coupled socioecological systems. Researchers should engage more clearly with movements between theories, models and data, and movements between ontology, epistemology and data.

Conclusions Landscape ecology can — and shouldaccommodate social theory in its analysis but from a different premise than is currently often the case. The
\end{abstract}

L. Gerrits $(\bowtie)$

Institute for Housing and Urban Development Studies,

Erasmus University Rotterdam, Rotterdam, The

Netherlands

e-mail: gerrits@ihs.nl proposed operations will contribute to a complexityinformed understanding of human behavior in coupled socio-ecological systems.

Keywords Social theory - Theory transformation . Model transformation $\cdot$ Critical realism

\section{Introduction}

This special issue problematizes the development and use of social theory in landscape ecology, with attention to the lack of generalized or generalizable theory from the scattered (case) studies that have been published within the field. These are pressing issues and the fact that they have been on the agenda for quite a while (Wu and Hobbs 2002, 2007; Wu 2008; Lambin and Meyfroidt 2010) is testimony to their vexing nature. The observation that social theory is developed in a haphazard way is not unique to landscape ecology. In fact, many social scientific fields struggle to compile their findings into general theories of social behavior. The issue can be found in both heavily fragmented fields such as Public Administration (e.g. McCurdy and Cleary 1984; Miller and Jaja 2005; Ostrom 2008; Mainzer 2016) as well as fields that tend to uphold the image of more coherence, such as social psychology (e.g. Earp and Trafimow 2015; Bardi and Zentner 2017). Proposed remedies_-all which can be 
found across fields-include more stringent use of research methods (e.g. Bailey 1992), larger sample size (e.g. Fraley and Vazire 2014; Maxwell et al. 2015), preregistration and full-disclosure of the analytical operations (e.g. Shrout and Rodgers 2018), and the possibility of publishing null results instead of focusing on research where the hypothesized causal relationships are proven (e.g. Bardi and Zentner 2017).

While these measures are sensible in many instances, they may fall short when it comes to research into coupled socio-ecological systems. This nexus challenges scholars to develop theories that link behavioral aspects to physical processes. It adds an extra level of ontological, epistemological, methodological and theoretical complexity to the analysis. The basic logic behind integrating social theory in landscape ecology, and any other type of field that deals with socio-ecological systems, is straightforward: if social and ecological systems exert mutual selection pressures, there shouldn't be an analytical boundary between them (Holling 2001; Gual and Norgaard 2010; Hird 2010; Weisz and Clark 2011). It spawned an entire school of research, with applications covering diverse topics such as the exploitation of forests and rainforests (Norgaard 1994; Lambin and Meyfroidt 2010; Bürgi et al. 2013), water resource management (e.g. Kallis 2010; Staveren et al. 2018), flood risk management (e.g. Tempels 2017), development of estuaries (e.g. Gerrits 2008, 2011), agriculture and its land use (Moreno-Penaranda and Kallis 2010), and hydrology (e.g. Sanderson 2018), to name just a few. The basic logic seems uncontested but there are major differences as to how it plays out in empirical research. Some may opt for a conceptual link in broader terms (e.g., Norgaard 1994), while others may access the coupling by investigating human agency in ecosystems as humans pass on knowledge about socioecological interaction based on their experience (e.g., Bürgi et al. 2013), and again others attempting to arrive at a hybrid model (e.g., Schlüter et al. 2012).

Whatever the approach followed, one can't get around the fact that it is the coupling itself that questions the assumptions underneath research and theory-building, and the ways in which research is enacted methodologically (Hersperger et al. 2010). More specifically: while there is a need to study coupled systems, there is no need to study them as if they work in the same way. The unifying assumptions in such studies, especially from a (complex) systems perspective (Briassoulis 2008), seem to glance over the fact that one deals with differences in kind rather than differences in degree. The methods and theories deployed in the studies need to reflect the fundamental differences between social and physical systems. There are limited gains if the social realm is researched in the same way as a physical system, and vice versa. This contribution to the special issue will provide an alternative ontology that is rooted in critical realism to recast research such that it does more justice the coupling of two different realms. To this end, I will first briefly discuss the nature of social theory in the light of coupled systems before, second, discussing some of the fundamental differences between the two realms. Next, I'll discuss five ways in which coupled systems are being researched. These are regarded as expressions of how researchers attempt to deal with these differences mentioned in the previous sections. The last part of the paper brings these observations together and explains how movements between theories, models and data, and movements between ontology, epistemology and data, will produce more robust knowledge about socio-ecological systems.

\section{The emergence of social theory}

A principal distinction exists between the general, conceptual idea of coupled systems on the one hand, and the analysis of the mechanisms of such coupled systems on the other hand (Sanderson 1990). While the first articulates the coupling on a conceptual level without much further analytical depth, the second attempts to map and explain the causal dependencies that exists between the coupled systems. It is the second version that this paper focuses on. In following this route, I subscribe to a particular view on landscape ecology that is contested by some (Kirchhoff et al. 2013). However, the concerns raised by Kirchoff and colleagues follow from the assumption, sometimes left implicit, that the two realms can be researched from a unified methodological and theoretical foundation. However, there are differences that one could consider so fundamental that ignoring them will lead to serious flaws in research (Danermark 2019). Contrary to what Kirchhoff et al. claim, this does not require a 'superscience' (2013, p. 37) but it does require researchers to depart from an ontology that facilitates those 
differences and that leaves room for the use of social theory. By the very definition of the purpose, this requires one to couple different systems analytically despite their fundamental differences (Weisz 2011). By extension, this is an interdisciplinary (Rammel, et al. 2007a, b; Weisz and Clark 2011; Danermark 2019) or transdisciplinary challenge (Pohl 2005; Rammel, et al. 2007a, b; Holzer et al. 2018; Sanderson 2018). It calls for landscape ecologists to get a much deeper understanding of the ways in which social theory is generated, and for social scientists to let go of their anthropocentric worldview (cf. Hird 2010). But while the interdisciplinary or transdisciplinary mode of research required for these topics itself is not necessarily unsurmountable (although not easy, see Jahn et al. 2012), it requires a more fundamental understanding of how social theory comes about.

A common view sees theory as a set of propositions about the relationship between factors-e.g., between farming and land-cover- that are to be tested for their explanatory power. Such propositions are organized in models (Hersperger et al. 2010) that can be tested empirically and in simulations. This particular way of generating social theory is intimately tied to the deployment of methods and techniques that comes with the practical limitations and possibility inherent to real-world research. Theories as provisional causal statements that can be falsified are but one type of theory. Following Althusser, one can classify theories into three distinct categories (O'Boyle and McDonough 2016; Gerrits and Marks 2017). The first category concerns the raw materials and grand ideas that define a research program. The complexity sciences and systems theories may be regarded as examples of such a broad program. The second category concerns theories as conceptual approaches that suggest novel ways of looking at reality within the boundaries of the research program. The third category concerns theories as discussed above: provisional causal statements that can be tested (Gerrits and Marks 2017). The three types of theory inform each other: while the second may be seen as a kind of dictionary providing concepts that shape the way we see the world, the third generates empirical evidence that allows one to define, redefine or reject those concepts. Over time, and with enough thought and evidence, the interaction between the two may give reasons to reconsider the grand ideas from the first category. To be clear, concepts and ideas can stem from creative thought and experiential learning as much as from empirical evidence.

Theories in the second category-the conceptscan be considered the pivot of the production of theory (O'Boyle and McDonough 2016). But important as they may be, there are also issues inherent to the nature of these theories: they are historically contextualized, carry contradictions, and can be seen as ill-defined, abstract and generally non-testable (Mouzelis 1995). Despite these issues, it remains a key theoretical category as it directs the ways (note the plural) in which the world may be seen. Self-organization, for example, is one of those concepts that is as ubiquitous as ill-defined when applied to spatial problems (de Bruijn and Gerrits 2018). To one researcher, it means the emergence of a spatial structure without superimposed design; to another it means a set of activities that actors undertake to develop a given space. There are more contrasting and sometimes contradicting varieties (ibid.) that work for a particular subset of researchers but may appear frustratingly ambiguous to other researchers because of the presence of differences that are left implicit. Another example is framing. Framing (e.g., Fischer and Forester 1993) draw the researcher's attention to the ways in which dominant images about environmental problems shape environmental policies, a suggestion that was inspired by the post-modernist turn in the social sciences (i.e., theories of the first category). 'Framing' defies empirical testing in the positivist sense of the word and can be ambiguous in its empirical appearance. Yet there is no denying that any researcher in the field understands the importance of the concept when it comes to understanding where environmental issues come from and how they are dealt with currently.

Althusser's classification is a reminder that social theory comes in more than one shape, and that each type is produced in a different but reciprocal fashion. The question how one can arrive at generalizable statements of social behavior in coupled socioecological systems needs to consider the differences, as such necessitating a deeper understanding of the empirical cycle of discovery (Wuisman 2005). I'll start by pointing at some of the obvious differences between the social and physical realm to show that a research strategy applied to one may not yield the same depth of insight in the other. 


\section{Differences between social and physical processes}

Timescales

The first, and probably most obvious one, concerns timescales. From a distance, it seems as if changes in natural systems take much more time to complete than changes in social systems, and by a large margin, too (Sivapalan and Blöschl 2015). While it is possible to reconstruct an ecosystem's development over decades or centuries in a reliable manner, this is much less possible with the behavioral patterns and their causes in social systems. A closer look shows that time is decidedly layered: related changes in one system play out simultaneously over different timescales (Risser 1987; Marceau 1999). This goes for both type of systems. Consider hydrological and morphological changes in rivers: erosion and local changes to a river's geometry can play out in a short matter of time, while the (subsequent) morphological changes may take decades or centuries to appear (Gerrits 2008; Sivapalan and Blöschl 2015). Likewise, communities living along the same river may change their preferences and behavioral patterns in a relatively short time span while institutional and regulatory change may take years, and engineering works decades before becoming effective (e.g. Gerrits and Marks 2008; Marks et al. 2014; Termeer et al. 2017). As such, one cannot simply mirror one timescale to the other. To complicate matters further, one may also have to discern between biological processes in humans and behavioral processes, the first having more longevity than the second (Newton 2003). Changes (in both realms) are often characterized as punctuated (Eldredge and Gould 1972; Gerrits 2008; Gersich 1991; Baumgartner and Jones 1993; Scheffer et al. 2001). Following Elias, Newton (2003) differentiates between temporal flux and long-term patterns in order grapple with the differences in pace as revealed in both systems. The analytical problem here is that the (reciprocal) influence between ecological and social systems is direct but the resulting changes visible at different timescales. An immediate consequence of these considerations is that time and pace are neither a given, nor always synchronized in coupled systems. In other words, the researcher must not assume congruence of timescales when doing research.
Human agency

The second issue concerns agency. Human agency constitutes a qualitative difference compared to agency (whatever that may be) in ecological systems, ${ }^{1}$ with the former having the reflexive capacity to anticipate, plan, forecast, adapt and deliberately change behaviors, sometimes overnight. If anything, it means that people in similar situations may or may not behave in similar ways. That is: agency causes variance in human behavior, even if other conditions remain similar across instances. This complicates the reconstruction of what has happened and why it has happened; and inhibits the extent to which one may make reliable predictions about human behavior. Certainly, humans can be expected to adapt to ecological changes but the direction of those adaptations is anything but a given. How a certain adaptation pans out can only be learned over time (Hrebiniak and Joyce 1985). This also highlights the relationship between agency and timescale (Hartvigsen et al. 1998). Adaptations - as responses to changes within the ecosystem - take place at different timescales and are essentially omnidirectional until the environment selects for a certain behavior (Nelson and Winter 2004; Nelson 2006; Hatfield-Dodds et al. 2007). The punctuated nature of changes in both systems hampers the ability of humans to forecast and anticipate each change correctly (Gunderson 2001a, b). Indeed, randomness may be an important factor in the selection processes. The implication is that any attempt at understanding human agency in ecosystems requires that one does not only observe behaviors but also explain what has caused these behaviors, i.e., the 'why' question in addition to the 'what' question. As human behavior is hard to predict beyond truisms, substantive knowledge and social theory play a keyrole in understanding human agency (Strang 2009).

\footnotetext{
1 A possible exception may be the research that attempts to link ecological systems to human behaviour via biology to identify how ecological change leads to genetic variation, selection and retention, which then impacts behaviour of humans in ecosystems (Hird, 2010; Weisz, 2011). While fascinating, this area is still very much in its infancy and too complex to be summarized for the present argument.
} 
Conditional nature of observations

The third issue concerns the difference between observations that hold across all cases, and observations that are local in place and temporal in time. This difference concerns the extent to which findings can be considered conditional. Overall, most scientists desire to identify those patterns that can stand the test of falsification and remain constant across all instances. The fundamental difference between ecological systems and social systems is that the characteristics of the latter prohibit researchers from finding such patterns. $^{2}$ Agency is contingent and so people may respond differently to the same incentive when in different situations. What people do, how they do it and why they do it, is something that relates strongly to the specific circumstances at the time of observation. As such, it is oftentimes not possible to find observations that remain true for all instances. Certainly, mapping values through surveys is an important step in understanding human actions regarding ecology (Buchecker et al. 2007). Such an approach may give an idea of persistent attitudes, for example that adults are not easily persuaded to change their attitudes towards nature and environmental protection (Kaiser et al. 2014). However, survey materials such as these are still limited when it comes to explaining why and how humans do certain things in certain ways because of the great variety of behaviors they display under various conditions-quite unlike physical principles that remain constant no matter the situation. An acute consequence of this is that findings from a particular instance may be refuted when used in another instance, not because the original findings were wrong but because they were bound to that particular instance (Byrne 2002, 2005).

\section{Unpredictability}

These first three issues prohibit a generalization across systems and a generating of solid theories that hold true across all instances. This, in turn, prevents one from rendering straightforward predictions. A general

\footnotetext{
2 Physical processes may also show local differences, of course, see e.g., Helldén (2003) on desertification or Indarto and Mutaqin (2016) on deforestation. However, those differences are linked to human activities instead of constituting a property of the physical process alone.
}

law concerns the true occurrence of something independent of time and place. This independence is what generates predictive power. General laws have four features that allow permanent explanation and prediction: (1) they must be rooted in empirical observations; (2) they must apply regardless of time and space; (3) they must represent the truth; (4) there must be natural necessity (Mitchell 2009). This is a tall order. Contingency and the occurrence of non-ergodic chance events inhibit any causal pattern from becoming perfectly repetitive. This does not mean that everything that is social is also random-some parts of social life show a considerable degree of recurrencebut it implies that deviation is always possibly and that a genuine understanding of social behavior needs to consider change as much as repetition. Scientific workarounds include the use of the ceteris paribus clause, small world reasoning, and the use of restricted experiments, among others (Gerrits 2012). Within such strict limits, general laws as characterized by Mitchell may be articulated but with the caveat that they fall apart once the restrictions are loosened. The restrictions themselves derive from the ideal of finding general laws. That is to say, they are put in place because of the expectation that one will find regularities in the 'noise' of social data. It may be more realistic to let go of that desire than to keep working with brittle restrictions.

\section{The production of knowledge of coupled systems}

The discussion about the (im-)possibility of identifying general laws cannot be separate from a discussion about the production of knowledge. It appears reasonable to deploy methods and techniques from the natural sciences if the goal is to find general laws in social systems. The debate about the question whether methods from the natural sciences can be deployed successfully when researching social systems goes back a long way and can be succinctly summarized as: the social sciences have failed to emulate the natural sciences in terms of methods and theories, not because the social sciences are less rigorous (see e.g. Ragin and Amoroso 2010) but because the social realm is a vastly different world than the natural world for the reasons discussed above. This is not the place to reiterate that debate in its entirety (see e.g. Flyvbjerg 2001; Flyvbjerg et al. 2012 for an in-depth discussion). 
There have been, and still are, certain fields in the social sciences that attempt to emulate the natural sciences with the expectation of finding similar causal constructs. This usually does not deliver the desired results, or delivers results that are border on truisms. Consider Bardi and Zentner's observations about social psychology, a field "[...] consisting of many parallel mini theories and isolated effects" (2017, p. 2). Certainly, some findings can be falsified if the research has an extremely narrow focus (i.e., the restrictions mentioned above). However, doing that ignores much of social life's complexity, in turn rendering results decidedly vulnerable once exposed to those complexities. It is useful to cite the authors in full: "When many potentially relevant factors are left out of a study, for reasons of parsimony or control, they do not therefore cease to influence the behavior of interest. Rather, their influence becomes imponderable - it can be negligible in one study, but more prominent in another. The inconsistent influence of factors that are left out of studies is bound to result in inconsistent findings." (ibid.).

The authors recommend integrating more complexity (as expressed in terms of environmental factors) into the analysis. The analysis and recommendation resonate with the points made above: human behavior is contingent and conditional. The scattered findings and 'mini theories' are exactly what one would expect to find if one accepts that contingency instead of aiming for general causal laws. It is not a weakness but the hallmark of social reality. Explanation is still possible, if it is understood that the explanation identified is local in place and temporal in time. Adding more observations may alter the recurring pattern (Byrne 2005, 2009). From the perspective that the natural and social systems are of the same nature, and thus should be researched with the same theories and methods, the social sciences are in a bad shape: severely fragmented, "not ready" (IJzerman et al. 2020, p. 3), and not able to move beyond truisms without many caveats (Bavel et al. 2020). From the perspective that accepts the conditional and contingent nature of social life, however, nothing much is lost. The challenge is to tailor methods and techniques to deal with this, instead of lamenting an imaginary problem.
Five different approaches in the production of knowledge

Five principal ways of enacting research into coupled systems have emerged in response to the issues identified above. The first concerns the modelling and simulation of interactions (e.g. Waring and Richerson 2011; Lu et al. 2018; Ursino 2019). Modelling is "[...] studying a complex phenomenon in the real world by first constructing and then studying a model of the phenomenon." (Weisberg 2007, p. 208) The empirical basis for the models may differ. Indeed, the explicit purpose of modeling is to work with simplifying assumptions-stripping complexity to the bare bones, as it were-and can be used to negate lack of empirical data (Lenhard 2005). Indeed, modelling is primarily a form of theorizing about what could plausibly happen (Weisberg 2007). Subsequently, modelling can deal with issues such as timescales by simply simulating longer time series. It may also deal with human agency by modelling specific characteristics, albeit in a very limited sense. The simplifying assumptions and speculations are both a strength and a weakness because of the extent to which they are detached from the reality they attempt to emulate. Importantly, modelling has difficulties with theories from the second category as they are usually broad, inexact, ambiguous and hard to quantify-the latter being a key step in the modelling process.

The second approach concerns what Weisberg (2007) calls Abstract Direct Representation or ADR. ADR engages with the real world without the mediation of a theoretical model, e.g. by compiling social statistics, remote sensing data, maps, etc. directly into research (e.g. Hirayama et al. 2020; Yue et al. 2020). The empirical basis for this type of research is situated in quantified, empirical, often stacked or composite data. Such data performs very well when it comes to (multiple) timeseries but much less when it comes to agency and context. As for context: one could argue that many statistical operations are very much about decontextualizing data (Byrne 2002). This is not to say that context is unimportant. At the very least, researchers collect data from specific places with the aim of explaining that specific phenomenon. However, the specific conditions under which humans act in certain ways cannot be considered because the approach 
insensitive to it. Likewise, human agency goes out of focus. As with modelling, ADR represents the third category of theory building as identified by Althusser. There may be a link to theories from the second category but it is a weak and indirect link. ADR seemingly represents the social and physical world directly. As such, it appears as if questions about human agency and conditions can be resolved by collecting more data. While it is always useful to have more data, it won't solve the persistent issue that ADR doesn't generate the level of comprehension of human behavior that theories from the second category do.

The third approach concerns the use of detailed, single case studies (e.g. Norgaard 1994; Gunderson 2001a, b; Moreno-Penaranda and Kallis 2010; Staveren et al. 2018). Although case studies take on various forms in various fields (Ragin and Becker 1992; Byrne and Ragin 2009), common aspects of case studies, as e.g., found in the current domain, include detailed empirical material regarding one specific ecosystem, an attempt to capture the full empirical complexity of a particular coupled system, and an attempt at generating theory and testable propositions (George and Bennett 2005). The materials are characterized by depth as well as longevity. They go a long way towards understanding human behavior in specific contexts, i.e., it is good at generating conditional statements. Time can be accounted for. The amount of empirical data needed to make a case study work is considerable. What is gained in terms of depth and longevity is lost in terms of generalizability. That is: case studies struggle with the question if a detected pattern is unique for a given case or something that reoccurs across cases. A way out of this is to carry out comparative case studies (Rihoux and Lobe 2009) but there will always be a trade-off between in-depth, case-based knowledge and cross-case comparison (Gerrits and Verweij 2018). Importantly, case studies allow experimentation with theory-building in the second category. The direct and in-depth confrontation between concepts and case-based materials allow conceptual refinement as well as conceptual creativity that could, in the long run, inform theories from the third category.

The fourth approach concerns a conceptual one, where theoretical concepts are used to make sense of empirical observations, the latter of which are not necessarily full case studies (e.g. Liu et al. 2007;
Rammel, et al. 2007a, b). Concepts serve as heuristic devices (Rammel, et al. 2007a, b) and empirical data is used to substantiate the concepts. The primary purpose of this approach is to enhance the researcher's understanding of the object of interest. It is more geared towards exploration as to what concepts may add than it is about rigorous testing (e.g., in timeseries). Much of its success hinges on the researcher's ability to build plausible links between concepts and observations of human behavior. To some extent, this approach presents a mix of theorizing and empirical research and could be considered a form of case study research (Ragin and Becker 1992). The reason for identifying such studies as a separate strand is that they serve a somewhat different purpose and do so in a different manner. This approach lacks empirical rigor. Analysis and interpretation cannot be assigned to technical operations. By its very nature, this approach sits squarely in the second category of Althusser's classification.

The fifth approach concerns the use of mixed methods design to address the dynamics of each system with the methods and concepts that do justice to those, e.g. combining numerical data pertaining to the ecosystem with qualitative case studies of the social system that coevolves with the ecosystems (e.g., Gerrits 2008). The main purpose of a mixed-methods approach is to relate different types of data to capture more of the complexity of coupled systems without sacrificing the rigor necessary for pertinent insights (Poth 2018). This can be done e.g., in order get to grips with stacked timescales or the vagaries of human behavior. Naturally, it is a data-hungry and laborintensive way of working. While it has potential to negate some of the issues raised above, the main drawback concerns the complexity of integrating the various methods into a coherent whole. Indeed, this type of research often becomes 'containerized' with each method addressing a specific aspect but without the necessary integration of those aspects, thus keeping the research fragmented despite the possibility of integration (Liu et al. 2007; Gual and Norgaard 2010; Jahn et al. 2012). As such, multi-method research tends to be either sequential (one method after the other) or parallel (two methods carried out simultaneously) but without actual merging taking place. It is difficult to do interdisciplinary, mixedmethods research in order to create a common understanding (Holzer et al. 2018; Danermark 2019) 
but one may also argue that any new insight has value, no matter the combination of the methods.

The five types-admittedly a somewhat crude distinction - relate also to the nature of the data used. While the first and second rely primarily on quantitative data, the third and fourth usually utilize qualitative data. The fifth offers scope to combine different types of data. Above all, the five types express the ways in which researchers attempt to navigate the issues of agency, timescales, context and generalizability. In doing so, they move back and forth between the second and third type of social theory. Unfortunately, these movements are rarely acknowledged and explained. Likewise, researchers rarely account for their ontological and epistemological views when making these movements. This leaves the reader guessing about the way in which the results need to be tied together and understood.

\section{Traveling back and forth}

Moving between theories, models and data

An approach that does justice to the complexities of coupled socio-ecological systems fosters an acute awareness of the theoretical and analytical movements between theories, models, and empirics of both types of systems. With that first step, two movements need to be articulated. Weisberg's (2007) model of theorizing may serve as a heuristic for this step so I will expand it for the current argument. ${ }^{3}$ As mentioned above, Weisberg differentiates between theoretical models on the one hand and abstract representations of the empirical world on the other. Modelling, that is: the process of constructing a model, constitutes an indirect way of learning about the real world. The model is treated as an independent theoretical object. Naturally, there must be correspondence between the

\footnotetext{
3 Weisberg's model was developed with formal or abstract modelling in mind, and considers how those models relate to the real world. While the current paper is not about abstract modelling in the strict sense as used by Weisberg, the differentiations and movements described between different modes are equally useful for the present purpose. In the social sciences, the term 'model' is applied in a broader sense than in Weisberg's examples for developing the above described distinction. I follow Marks et al. (2019) who regard models as the theoretical apparatus employed in social sciences.
}

model and the real world (2007, p. 224) but only in certain aspects as modelling is about simplification of the real world so that researchers can theorize about relationships. The ADR also relates to the real world but does so without the help of a theoretical model: the data is structured using the current methodological operations. The results constitute representations of the world that give access to said world for the generation of explanations (Hempel and Oppenheim 1948) but they can be considered 'messy' as accurate representations are difficult to establish (Knuuttila 2011). The first movement is therefore between theoretical models and representations of the world to negotiate the simplifications of models on the one hand and the messy representations on the other.

The second movement, then, takes place between source domain and target domain (Marks et al. 2019), here to be understood as a movement between ecological systems and social systems. Two knowledge transfers are possible. In the first, the original model developed for the source domain represents that source domain correctly but not the target domain, and it is not conceivable that it could be made to fit the target domain. In this case, the researcher will have to accept that the two systems need to be analyzed with discrete theories and methods. The second transfer concerns the transformation of a theoretical model from the source domain to the target domain such that it fits the target. Here, certain properties of the original theoretical model may be retained but others may have to be modified because of the specific properties of the target domain (e.g. to account for social action, see Marks et al. 2019).

The first kind of knowledge transfer may be possible within certain strict boundaries but it is the second kind that is central to the current argument. After all, it is highly unlikely that a method or theory developed for one system holds equal explanatory power for the other system. The extent of transformation from source to target domain is not a given. A strict transformation and application cannot accommodate certain features of the target domain. Likewise, in a rather casual transfer and application, any two things can be regarded "as arbitrarily similar" (Bolinska 2013, p. 220). The transformation highlights that the model and the target domain are isomorphic when it comes to the syntactic structure (i.e. the set of causal mechanisms represented) and the semantic structure (i.e. the vocabulary or conceptual language 
used to represent the object of interest) (Marks et al. 2019). The target domain is addressed by finding functional equivalents to the both structures of the original model. This operation enables researchers to learn indirectly about target domain by manipulating and analyzing the source model. Such learning through isomorphism is pivotal to understanding the dynamics of coupled systems. After all, a correct transfer requires articulated awareness of the nature of the objects and their relationships (Woody 2004) as these need to be mapped and explained in the research. Mapping the movements, expressing the considerations for the transfer and the discussing the final theoretical model as a plausible representation of the coupled systems is pivotal in achieving awareness about the differences between systems.

Moving between ontology, epistemology and observations

An approach that acknowledges the complexities of coupled systems also understands that epistemology and ontology are not a given. Interdisciplinary research requires one to move back and forth between epistemology, ontology and data (Danermark 2019). Questions about the nature of reality is not just 'stuff for philosophers.' All too often, researchers are seemingly unaware of the ontological and epistemological status of their causal claims. ${ }^{4}$ Likewise, readers are left with ample room to interpret and question results. Naturally, such room is somewhat inevitable, but a better articulation of one's position vis-à-vis the nature of reality and the tools one deploys to uncover said reality goes a long way towards establishing more robust theories. This is especially important when one deals with different types of systems (Klein 2008). It requires a recalibration of given wisdoms and "new cultures of evidence" (2008, p. 117), and unlearning established practices (Gorski 2013).

The implicit or explicit assumption that social and physical processes are governed by the same causal mechanisms and can be uncovered using the same techniques hinges on the researcher's worldview. But as much as physical processes can be approached in a positivist fashion, this does not travel far when it comes to social processes. As argued above, social

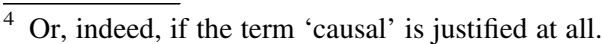

processes are conditional and restrictive measures such the ceteris paribus clause needed to 'control' for real-world variation fall short.

Critical realism provides an ontology that does considerably more justice to the conditional and openended nature of reality (Price 2014) than positivism does. For positivist, there is "[...] no ontological distinction between natural and social entities [...]" (Gorski 2013, p. 660) while interpretivists and constructivist move to the other far end by assuming that all objects, both social and natural, are socially and linguistically constructed (ibid.). Critical realism, in the way as developed by Bhaskar (2008) ${ }^{5}$ takes the position that there is a reality that can be known but that this reality is not directly accessible. Instead, one should think of reality as being stratified into three layers: the real, the actual and the empirical. Mechanisms that can cause things to happen are potentially always present but only activated or triggered under conditions. Events and processes in the real world (the second dimension of stratification) and the effects of the mechanisms (third dimension) can be observed and researched as they take place (Gerrits and Verweij 2013). As such, critical realism assigns meaning to the observation that people behave differently under various conditions without suggesting that all behavior is random or that no patterns can be detected. Instead, the question shifts to the conditions that activate certain behaviors. In doing so, it helps researchers navigating the gaps between the social and physical realm.

Reality being stratified opens the possibility of making the movements described in this paper. While physical processes may be traced in the second layer directly and social processes traced more conditionally via the third layer, it is all done from within a coherent ontology that does not walk into the traps of extreme positivism or post-positivism. It does require comparative research to discern between singular (unique) instances and recurring patterns. A singular case will do little to show those differences because of the attribution problem. However, singular cases can still be useful in generating propositions about the possible mechanisms one would like to look at.

\footnotetext{
5 Originally, Bhaskar did not use the term 'critical realism' but called his ontology 'transcendental realism' (Losch 2009; Easton 2010). However, this school of thought has become widely known as critical realism.
} 
Altogether, critical realism provides the ontology in which the movements between source and target domain, between physical and social objects, and the model transformations that are required to facilitate those movements, can be embedded and made sense of. To restate: these are actual operations that can be done-and should be done-when researching coupled socio-ecological systems. Danermark (2019) provides a concrete, stepwise guide for such research.

\section{Conclusions}

The special issue problematizes the use of social theory in landscape ecology, arguing that there is too much fragmentation, too little generalization from individual case studies, and little methodological development. The alternative angle presented in this paper showed that the criticism is justified only if one assumes that both systems can be researched in the same way, and only if one assumes theory to come in one kind only. I've argued that both assumptions don't withstand closer scrutiny, and have shown how an awareness and articulation of differences-empirical, methodological, epistemological, and ontologicalcome a long way towards the development of more robust theories about coupled systems. It requires researchers to move back and forth between these various aspects and to communicate about it so that readers can get a better understanding of the status of the findings. The idea that social behavior is conditional explains why no general, unconditional social theory of landscape ecology is possible. But this does not mean that research would be fruitless. Quite the opposite: showing what conditions coincide with certain behaviors contributes significantly to a complexity-informed understanding of coupled socioecological systems. The field may not be fragmented because of failures in research practices but rather because reality features these different layers that researchers are starting to see glimpses of.

Acknowledgements I would like to thank the two anonymous reviewers for their constructive feedback on an earlier version of this paper.

Open Access This article is licensed under a Creative Commons Attribution 4.0 International License, which permits use, sharing, adaptation, distribution and reproduction in any medium or format, as long as you give appropriate credit to the original author(s) and the source, provide a link to the Creative Commons licence, and indicate if changes were made. The images or other third party material in this article are included in the article's Creative Commons licence, unless indicated otherwise in a credit line to the material. If material is not included in the article's Creative Commons licence and your intended use is not permitted by statutory regulation or exceeds the permitted use, you will need to obtain permission directly from the copyright holder. To view a copy of this licence, visit http://creativecommons.org/licenses/by/4.0/.

\section{References}

Bailey MT (1992) Do physicists use case studies? Thoughts on Public Administration Research. Public Adm Rev 52(1):47.

Bardi A, Zentner M (2017) Grand challenges for personality and social psychology: moving beyond the replication crisis. Front Psychol. https://doi.org/10.3389/fpsyg.2017.02068

Baumgartner FR, Jones BD (1993) Agendas and instability in American Politics, 1st edn. University of Chicago Press, Chicago

Bavel JJV, Baicker K, Boggio PS, Capraro V, Cichocka A, Cikara M, Crockett MJ, Crum AJ, Douglas KM, Druckman JN, Drury J, Dube O, Ellemers N, Finkel EJ, Fowler JH, Gelfand M, Han S, Haslam SA, Jetten J et al (2020) Using social and behavioural science to support COVID-19 pandemic response. Nat Hum Behav 4(5):460-471

Bhaskar R (2008) A realist theory of science. Routledge, London

Bolinska A (2013) Epistemic representation, informativeness and the aim of faithful representation. Synthese 190(2):219-234.

Briassoulis H (2008) Land-use policy and planning, theorizing, and modeling: lost in translation, found in complexity? Environ Plan B 35:6-33

Buchecker M, Kianicka S, Junker B (2007) Value systems: drivers of human-landscape interactions. In: Kienast F, Wildi O, Ghosh S (eds) A changing world: challenges for landscape research. Springer, Netherlands, pp 7-26

Bürgi M, Gimmi U, Stuber M (2013) Assessing traditional knowledge on forest uses to understand forest ecosystem dynamics. For Ecol Manage 289:115-122

Byrne D (2005) Complexity, configurations and cases. Theory Cult Soc 22(5):95-111

Byrne DS (2002) Interpreting quantitative data. SAGE Publications Ltd, New York

Byrne DS (2009) Complex realist and configurational approaches to cases: a radical synthesis. In: Byrne DS, Ragin CC (eds) The Sage handbook of case-based methods. SAGE Publications, New York, pp 101-112

Byrne DS, Ragin CC (2009) The Sage handbook of case-based methods. Sage Publications Ltd, New York

Danermark B (2019) Applied interdisciplinary research: a critical realist perspective. J Crit Realism 18(4):368-382

de Bruijn E, Gerrits L (2018) Epistemic communities in urban self-organization: a systematic review and assessment. J Plan Lit. https://doi.org/10.1177/0885412218794083 
Earp BD, Trafimow D (2015) Replication, falsification, and the crisis of confidence in social psychology. Front Psychol. https://doi.org/10.3389/fpsyg.2015.00621

Easton G (2010) Critical realism in case study research. Ind Mark Manage 39(1):118-128

Eldredge N, Gould SJ (1972) Punctuated equilibria: an alternative to phyletic gradualism. In: Schopf TJM (ed) Models in paleobiology. Cooper \& Co, San Francisco, pp 82-115

Fischer F, Forester J (1993) The argumentative turn in policy analysis and planning. Duke University Press, Durham

Flyvbjerg B (2001) Making social science matter: why social inquiry fails and how it can succeed again. Cambridge University Press, Cambridge

Flyvbjerg B, Landman T, Schram SF (2012) Introduction: new directions in social science. In: Flybjerg B, Landman T, Schram SF (eds) Real social science: applied phronesis. Cambridge University Press, Cambridge

Fraley RC, Vazire S (2014) The N-pact factor: evaluating the quality of Empirical Journals with respect to sample size and statistical power. PLoS ONE 9(10):e109019

George AL, Bennett A (2005) Case studies and theory development in the social sciences. The MIT Press, Cambridge

Gerrits L (2008) The gentle art of coevolution: a complexity theory perspective on decision making over estuaries in Germany, Belgium and the Netherlands. Erasmus University Rotterdam, Rotterdam

Gerrits LM (2011) A coevolutionary revision of decision making processes: an analysis of port extensions in Germany, Belgium and the Netherlands. Public Adm Q 35(3):309-339

Gerrits L (2012) Punching clouds: an introduction to the complexity of public decision-making. Emergent Publications, Litchfield, AZ

Gerrits LM, Marks PM (2008) Complex bounded rationality in dyke construction; path-dependency and lock-in in the emergence of the geometry of the Zeeland delta. Land Use Policy 25(3):330-337

Gerrits LM, Marks PM (2017) Understanding collective decision making. Edward Elgar Publishing, Cheltenham, UK

Gerrits LM, Verweij S (2013) Critical realism as a metaframework for understanding the relationships between complexity and qualitative comparative analysis. J Crit Realism 12(2): 166-182

Gerrits L, Verweij S (2018) The evaluation of complex infrastructure projects. Edward Elgar Publishing, Cheltenham, UK

Gersich CJG (1991) Revolutionary change theories: a multilevel exploration of the punctuated equilibrium paradigm. Acad Manag Rev 16(1):10-36

Gorski PS (2013) What is critical realism? And why should you care? Contemp Sociol 42(5):658-670

Gual MA, Norgaard RB (2010) Bridging ecological and social systems coevolution: a review and proposal. Ecol Econ 69(4):707-717

Gunderson LH (2001a) Managing surprising ecosystems in southern Florida. Ecol Econ 37(3):333-484

Gunderson LH (2001b) South Florida: The reality of change and the prospects for sustainability: managing surprising ecosystems in Southern Florida. Ecol Econ 37(3):371-378
Hartvigsen G, Kinzig A, Peterson G (1998) Use and analysis of complex adaptive systems in ecosystem science: overview of special section. Ecosystems 1(5):427-430

Hatfield-Dodds S, Nelson R, Cook D (2007) Adaptive governance: an introduction, and implications for public policy. Adapt Govern 13

Helldén U (2003) Desertification and theories of desertification control: a discussion of Chinese and European concepts. In: Proceedings of the China-EU workshop on integrated approach to combat desertification, pp 94-104. https:// portal.research.lu.se/portal/en/publications/desertificationand-theories-of-desertification-control-a-discussion-ofchinese-and-european-concepts(6820d22c-736c-46d19a6e-0d8f79b1bfa4).html

Hempel CG, Oppenheim P (1948) Studies in the logic of explanation. Philosophy Sci 15(2):135-175

Hersperger AM, Gennaio M-P, Verburg PH, Bürgi M (2010) Linking land change with driving forces and actors: four conceptual models. Ecol Soc. https://doi.org/10.5751/ES03562-150401

Hirayama H, Tomita M, Hara K (2020) Quantitative monitoring of changes in forest habitat connectivity following the great eastern Japan earthquake and tsunami. Landsc Ecol. https://doi.org/10.1007/s10980-020-01034-4

Hird MJ (2010) Coevolution, symbiosis and sociology. Ecol Econ 69(4):737-742

Holling CS (2001) Understanding the complexity of economic, ecological, and social systems. Ecosystems 4(5):390-405

Holzer JM, Carmon N, Orenstein DE (2018) A methodology for evaluating transdisciplinary research on coupled socioecological systems. Ecol Ind 85:808-819

Hrebiniak LG, Joyce WF (1985) Organizational adaptation: strategic choice and environmental determinism. Adm Sci Q 30(3):336

IJzerman H, Lewis NA, Weinstein N, DeBruine LM, Ritchie SJ, Vazire S, Forscher PS, Morey RD, Ivory JD, Anvari F, Przybylski AK (2020) Psychological science is not yet a crisis-ready discipline. https://doi.org/10.31234/osf.io/ whds 4

Indarto J, Mutaqin DJ (2016) An overview of theoretical and empirical studies on deforestation. 15

Jahn T, Bergmann M, Keil F (2012) Transdisciplinarity: between mainstreaming and marginalization. Ecol Econ 79:1-10

Kaiser FG, Brügger A, Hartig T, Bogner FX, Gutscher H (2014) Appreciation of nature and appreciation of environmental protection: how stable are these attitudes and which comes first? Eur Rev Appl Psychol 64(6):269-277

Kallis G (2010) Coevolution in water resource development. Ecol Econ 69(4):796-809

Kirchhoff T, Trepl L, Vicenzotti V (2013) What is landscape ecology? An analysis and evaluation of six different conceptions. Landsc Res 38(1):33-51

Klein JT (2008) Evaluation of Interdisciplinary and Transdisciplinary Research: A Literature Review. Am J Prevent Med 35(2):S116-S123

Knuuttila T (2011) Modelling and representing: an artefactual approach to model-based representation. Stud Hist Philos Sci 42(2):262-271 
Kuppers G, Lenhard J (2005) Validation of simulation: patterns in the social and natural sciences. J Artif Soc Soc Simul $8(4): 1-3$

Lambin EF, Meyfroidt P (2010) Land use transitions: socioecological feedback versus socio-economic change. Land Use Policy 27(2):108-118

Liu J, Dietz T, Carpenter SR, Alberti M, Folke C, Moran E, Pell AN, Deadman P, Kratz T, Lubchenco J, Ostrom E, Ouyang Z, Provencher W, Redman CL, Schneider SH, Taylor WW (2007) Complexity of coupled human and natural systems. Science 317(5844):1513-1516

Losch A (2009) On the origins of critical realism. Theol Sci 7(1):85-106

Lu Z, Wei Y, Feng Q, Xie J, Xiao H, Cheng G (2018) Coevolutionary dynamics of the human-environment system in the Heihe River basin in the past 2000years. Sci Total Environ 635:412-422

Mainzer LC (2016) Public administration in search of a theory: the interdisciplinary delusion. Admin Soc. https://doi.org/ 10.1177/009539979402600305

Marceau DJ (1999) The scale issue in the social and natural sciences. Can J Remote Sens 25(4):347-356

Marks PK, Gerrits LM, Bakker S, Tromp E (2014) Explaining inertia in restoring estuarine dynamics in the Haringvliet (The Netherlands). Water Policy 16(5):880

Marks P, Gerrits L, Marx J (2019) How to use fitness landscape models for the analysis of collective decision-making: a case of theory-transfer and its limitations. Biol Philos. https://doi.org/10.1007/s10539-018-9669-4

Maxwell SE, Lau MY, Howard GS (2015) Is psychology suffering from a replication crisis? What does "failure to replicate" really mean? Am Psychol 70(6):487-498

McCurdy HE, Cleary RE (1984) Why can't we resolve the research issue in public administration? Public Adm Rev 44(1):49

Miller HT, Jaja C (2005) Some evidence of a pluralistic discipline: a narrative analysis of public administration symposia. Public Adm Rev 65(6):728-738

Mitchell S (2009) Complexity and explanation in the social sciences. In: Mantzavinos C (ed) Philosophy of the social sciences: philosophical theory and scientific practice. Cambridge University Press, Cambridge, pp 130-145

Moreno-Penaranda R, Kallis G (2010) A coevolutionary understanding of agroenvironmental change: a case-study of a rural community in Brazil. Ecol Econ 69(4):770-778

Mouzelis N (1995) Sociological theory: what went wrong?: Diagnosis and remedies. Routledge, London

Nelson RR (2006) Evolutionary social science and universal Darwinism. J Evol Econ 16(5):491-510

Nelson RR, Winter SG (2004) An evolutionary theory of economic change (digitally reprinted). The Belknap Press of Harvard Univ. Press, Harvard

Newton T (2003) Crossing the great divide: time, nature and the social. Sociology 37(3):433-457

Norgaard RB (1994) Development betrayed; the end of progress and a coevolutioary revisioning of the future. Routledge, London

O'Boyle B, McDonough T (2016) Critical realism and the althusserian legacy: critical realism and the althusserian legacy. J Theory Soc Behav 46(2):143-164
Ostrom V (2008) The intellectual crisis in American Public Administration. University of Alabama Press, Alabama

Pohl C (2005) Transdisciplinary collaboration in environmental research. Futures 37(10):1159-1178

Poth C (2018) Innovation in mixed methods research. A practical guide to integrative thinking with complexity. SAGE Publications, New York

Price L (2014) Critical realist versus mainstream interdisciplinarity. J Crit Realism 13(1):52-76

Ragin CC, Amoroso LM (2010) Constructing social research: the unity and diversity of method, 2nd edn. SAGE Publications Inc, New York

Ragin CC, Becker HS (eds) (1992) What is a case? Exploring the foundations of social inquiry. Cambridge University Press, Cambridge

Rammel C, McIntosh BS, Jeffrey P (2007a) Where to now? A critical synthesis of contemporary contributions to the application of (co)evolutionary theory and discussion of research needs. Int J Sust Dev World 14(1):109-118

Rammel C, Stagl S, Wilfing H (2007b) Managing complex adaptive systems - a co-evolutionary perspective on natural resource management. Ecol Econ 63(1):9-21

Rihoux B, Lobe B (2009) The case for qualitative comparative analysis (QCA): adding leverage for thick cross-case comparison. In: Byrne DS, Ragin CC (eds) The SAGE handbook of case-based methods. SAGE, New York, pp 222-242

Risser PG (1987) Landscape ecology: state of the Art. In: Turner MG (ed) Landscape heterogeneity and disturbance. Springer, New York, pp 3-14

Sanderson MR (2018) Everything flows...unevenly: social stratification in coupled socio-ecological systems. Curr Opin Environ Sustain 33:51-57

Sanderson S (1990) Social evolutionism: a critical history. Blackwell, Basil

Sanderson SK (2001) Social evolution: overview. In: Smelser NJ, Baltes PB (eds) International encyclopedia of the social \& behavioral sciences. Pergamon, Oxford, pp 14279-14286

Scheffer M, Carpenter S, Foley JA, Folke C, Walker B (2001) Catastrophic shifts in ecosystems. Nature 413(6856):591-596

Schlüter M, MCallister RRJ, Arlinghaus R, Bunnefeld N, Eisenack K, Hölker F, Milner-Gulland EJ, Müller B, Nicholson E, Quaas M, Stöven M (2012) New horizons for managing the environment: a review of coupled socialecological systems modeling. Nat Resour Model 25(1):219-272

Shrout PE, Rodgers JL (2018) Psychology, science, and knowledge construction: broadening perspectives from the replication crisis. Annu Rev Psychol 69(1):487-510

Sivapalan M, Blöschl G (2015) Time scale interactions and the coevolution of humans and water. Water Resour Res 51(9):6988-7022

Strang V (2009) Integrating the social and natural sciences in environmental research: a discussion paper. Environ Dev Sustain 11(1):1-18

Tempels B (2017) Flood-resilience: a coevolutionary approach residents, spatial developments and flood risk management in the Dender Basin. University of Ghent, Ghent 
Termeer CJAM, Dewulf A, Biesbroek GR (2017) Transformational change: governance interventions for climate change adaptation from a continuous change perspective. J Environ Planning Manage 60(4):558-576

Ursino N (2019) Dynamic models of socio-ecological systems predict catastrophic shifts following unsustainable development. Sci Total Environ 654:890-894

van Staveren MF, van Tatenhove JPM, Warner JF (2018) The tenth dragon: controlled seasonal flooding in long-term policy plans for the Vietnamese Mekong delta. J Environ Planning Policy Manage 20(3):267-281

Waring TM, Richerson PJ (2011) Towards unification of the socio-ecological sciences: the value of coupled models. Geografiska Annal 93(4):301-314

Weisberg M (2007) Who is a modeler? Br J Philos Sci 58(2):207-233

Weisz H (2011) The probability of the improbable: societynature coevolution. Geogr Ann 93(4):325-336

Weisz H, Clark E (2011) Society-nature coevolution: Interdisciplinary concept for sustainability. Geografiska Annal 93(4):281-287

Woody A (2004) More telltale signs: what attention to representation reveals about scientific explanation. Philosophy Sci 71:780-793
Wu J (2008) Toward a landscape ecology of cities: beyond buildings, trees, and urban forests. In: Carreiro MM, Song Y-C, Wu J (eds) Ecology, planning, and management of urban forests. Springer, New York, pp 10-28

Wu J, Hobbs R (2002) Key issues and research priorities in landscape ecology: an idiosyncratic synthesis. Landsc Ecol 17(4):355-365

Wu J, Hobbs RJ (2007) Key topics in landscape ecology. Cambridge University Press, Cambridge

Wuisman J (2005) The logic of scientific discovery in critical realist social scientific research. J Crit Realism 4(2):366-394

Yue Y, Liao C, Tong X, Wu Z, Fensholt R, Prishchepov A, Jepsen MR, Wang K, Brandt M (2020) Large scale reforestation of farmlands on sloping hills in South China karst. Landsc Ecol. https://doi.org/10.1007/s10980-020-01026-4

Publisher's Note Springer Nature remains neutral with regard to jurisdictional claims in published maps and institutional affiliations. 